\title{
Niños errantes: la cámara como prisión o como puerta de salida en Largo viaje de Patricio Kaulen
}

\author{
Wandering children: the camera as a \\ prison or backdoor in Largo Viaje \\ by Patricio Kaulen
}

\author{
Catalina Donoso Pinto \\ Universidad de Chile, Chile \\ catalina.donoso@u.uchile.cl
}

- Resumen - Esta investigación analiza el recurso fílmico utilizado en una cinta chilena de 1967 en su intento por traducir el deambular urbano de su protagonista -un niño en situación de marginalidad- mediante el dispositivo cinematográfico. El filme estudiado es Largo viaje de Patricio Kaulen, antecedente del llamado Nuevo Cine Chileno pero también considerado en contradicción con los postulados estéticos y políticos de este movimiento. El análisis se concentra en el diálogo entre las posibilidades técnicas, las decisiones narrativas y la carga ideológica contenida en la construcción de un espectador implícito en la obra.

Palabras clave: infancia marginal, emancipación, Nuevo Cine Chileno, espectador.

- Abstract - This article analyzes the film resources used in a 1967 Chilean film as an attempt to translate the urban wanderings of its protagonist -a marginal childthrough its cinematic device. The film is Patricio Kaulen's Largo viaje, precedent of the New Cinema in Chile, that is also contradictory when it comes to Aesthetics and Politics within the frames of this movement. The analysis focuses on the dialogue between the technical possibilities, its narrative decisions and the ideological forces contained in the construction of the implicit viewer of the film.

Keywords: marginal childhood, emancipation, New Cinema in Chile, Audience. 
En su breve pero significativo libro Ser niño huacho en Chile (siglo XIX), Gabriel Salazar recupera una serie de historias de niños marginales, literalmente encontradas en los márgenes de documentos oficiales que el historiador revisaba con otros fines. Probablemente, el libro es el primer intento historiográfico por entregarles un lugar relevante como actores de la historia de este país. Huacho es una palabra de origen quechua que en Chile se suele utilizar como adjetivo para calificar algo o alguien que está solo o abandonado. Uno de sus usos más comunes es, sin embargo, un sustantivo que denomina a un niño que no tiene padre, ya que es fruto de un encuentro ilegítimo fuera del matrimonio" ${ }^{1}$. Me interesa destacar que "Salazar propone reconstruir la historia de los niños sobre la base de su contexto social, lo que llevaría a distinguir una niñez pobre o popular de una niñez patricia» (Rojas Flores, Los niños 31). En la misma línea, María Carolina Zapiola, en su artículo «Los niños entre la escuela, el taller y la calle. Buenos Aires 1884-1915», el cual estudia el impacto de las políticas de educación pública implantadas en ese periodo en Argentina, distingue una categoría de infante vinculado a la escuela, el «niñoalumno» (o «niño-alumno / trabajador» si se trataba del infante de clase popular), y otro, cuyo derecho a la educación es cuestionado y aplazado, de manera que su estatus de «niño» es reemplazado por la condición de «menor»:

Laxa categoría que hacía referencia a un conjunto urbano muy heterogéneo pero uniformemente ajeno a las pautas de comportamiento, circulación por el espacio, educación, trabajo, sexualidad y socialización familiar y extrafamiliar que las elites encontraban convenientes para los menores de edad (Zapiola 3).

En la primera mitad del siglo xix, etapa inicial de la era republicana en gran parte de Latinoamérica, se dictaron una serie de normas relativas a reducir y controlar la abundancia de niños solos en las calles de las ciudades. Su presencia suponía una suerte de amenaza para el orden, la seguridad y el ornato de la orgullosa urbe «que los ve 'aparecer' como si fueran una inundación peligrosa» (Salazar 89). Estas normativas, que fueron mantenidas y perfeccionadas a lo largo de ese siglo y del siguiente, prohibían la vagancia y la condenaban aún más que el trabajo infantil, que fue bastante discutido durante el período (Zapiola 10-1). Estas regulaciones no solo suponían la defensa de los ciudadanos ante la potencial conducta delictiva de los niños vagos, sino que también aparecían como una suerte de protección del propio niño vagabundo de las malas prácticas y desviaciones que su exposición al ambiente callejero representaba.

El famoso estudio de Phillipe Ariès, El niño y la vida familiar en el Antiguo Régimen, además de ser considerado una obra fundamental para la consolidación de la investigación historiográfica en torno a la infancia, es una pieza clave para

1 Y que refiere también a una de las raíces más fuertes del mestizaje en Latinoamérica: el de los hijos de madre indígena y padre español. Si ya en El laberinto de la soledad, Octavio Paz pusiera el énfasis en esta peculiaridad de la identidad mexicana ( «los hijos de la chingada»), el libro de Sonia Montecino, Madres y huachos, estudia también cómo esta figura familiar de madre-hijo-padre ausente sigue siendo una estructura prevalente en la conformación de los hogares latinoamericanos. 
entender esta última como una construcción redefinida en las sociedades occidentales a partir de los procesos de modernización. Esta perspectiva, ampliamente debatida en su momento, puso atención y cuestionó el rol de las instituciones (principalmente la familia y la escuela) que moldearon a esta nueva versión de la infancia y que, en su aparente motivación protectora, desarrollaron mecanismos de control y coerción que no hicieron más que mermar en sus derechos a los niños y que pretendían amparar y cuidar. Así, siguiendo el argumento de Ariès, las regulaciones dirigidas a proteger a los niños callejeros de la mala influencia de su propia libertad (y de paso a la ciudadanía respetable de los alcances nefastos de dicha independencia), tendieron a reducir los escasos espacios propios de expansión y recreación que estos niños tenían a su alcance. Tal como se lee en una ordenanza de policía de septiembre de 1874, datada en la ciudad de Los Ángeles en el sur de Chile:

Todo niño que se encontrare jugando o cometiendo desórdenes en las calles, será conducido por 24 horas al cuartel de policía, pudiendo sus padres rescatarlos pagando una multa de 25 centavos. Los que no paguen las multas [...] sufrirán una prisión de 24 horas por cada 25 centavos (Salazar 54).

Si bien la infancia que describió Ariès no se refiere específicamente a los niños marginales, sin hogar, presentados aquí, podemos afirmar que, tomando como modelo a la infancia burguesa ideal, el autor francés encontró en dicho grupo, aparentemente protegido y contenido, las marcas del sistema de vigilancia que operó (y opera) aún más drásticamente sobre aquellos niños que no pertenecen a las capas medias y altas de la sociedad. En The Child Savers: The Invention of Delinquency, Anthony M. Platt desarrolló extensamente cómo las conductas inapropiadas o sociopáticas consideradas «delictivas» pueden no solo entenderse como un comportamiento intrínsecamente negativo, sino también como una desviación que surge justamente a causa de que se crea una etiqueta diseñada perfectamente para calzar con ella (7). En su análisis, el corolario final nos presenta a la "invención de la delincuencia» como la consolidación del estatus social inferior y la dependencia de los niños y jóvenes de clase baja (177). Los niños de la calle -con o sin familia, pero sin lugar de pertenencia permanente por ausente o por inadecuado- deben ser destinados a otras instituciones de beneficencia en reemplazo de la falta de familia y escuela cuya motivación, puramente altruista y benefactora, Platt cuestiona al analizar en profundidad sus raíces y alcances políticos. No es mi intención ahondar en este último asunto estudiado por Platt, sino que, partiendo de dicha afirmación, señalar que no solo la infancia es una construcción moderna -como lo plantea Ariès- sino que su definición no contempla un grupo homogéneo y uniforme. De esta manera, el origen social designa, dentro de la misma insistencia en la dependencia y el control, tratos y expectativas disímiles para al menos dos clases distintas de niños.

La aproximación a la infancia que me ocupa en este trabajo se refiere a este grupo de infancia no privilegiada, cuyo entorno familiar es irregular y cuyo territorio de acción es principalmente la calle. La ausencia -permanente o temporal- de 
un hogar «bien constituido» los ubica en una situación de constante movimiento, ya sea para conseguir sustento, huir de las instituciones que pretenden contenerlos, o congregarse en grupos de niños en situación de idéntica precariedad. Ya vimos que a comienzos del siglo xix su condición de menores -según la nomenclatura desarrollada por Zapiola- los ubicaba como entidades móviles en las calles, ya entrado el siglo xx, y a causa de las leyes relacionadas con la restricción del trabajo infantil, permanecían aún más asociados a este espacio urbano: «De ahí que el trabajo infantil haya quedado restringido a sus expresiones menos visibles y más marginales, como [...] el comercio al detalle (en calles, mercados y ferias) y ciertas formas intermedias entre trabajo y vagancia» (Rojas Flores, Historia 495). Gabriel Salazar los describió como un elemento de rebeldía, en cuanto su independencia y carencia los llevó a forjarse una identidad que el entramado social les negaba. Postulo que dicha identidad se construye justamente en su capacidad (y necesidad) de movimiento, una energía que surge como potencial de sublevación y amenaza para la clase dominante «en un marco en el que [...] los sectores populares urbanos aparecían como inquietantemente móviles, desafiantes, inaprensibles» (Zapiola 15). Estos niños sin origen (el padre), sin pertenencia (el hogar o la escuela), encuentran su identidad en el espacio inestable de la calle. La película que pretendo analizar aquí acompaña a un niño marginal en su tránsito solitario (por desatendido) por las urbes. La narrativa del filme (Largo viaje de Patricio Kaulen, Chile, 1967) se centra en el desplazamiento del menor por la ciudad, como un trayecto preestablecido y lineal. Mi intención es problematizar esta presentación de un menor en desplazamiento a partir del cuestionamiento del artificio cinematográfico como mecanismo de pasividad y sus estrategias para reproducir el movimiento.

\section{EL MENOR Y LAS IMÁGENES EN MOVIMIENTO}

El cine fue alguna vez definido en cuanto maquinaria que reproduce o atrapa imágenes en movimiento ${ }^{2}$, y si bien desde el famoso texto de Gilles Deleuze, La imagentiempo, las aproximaciones al cine moderno muchas veces privilegian su función en cuanto dispositivo temporal, la coordenada espacial sigue siendo un elemento gravitante en la constitución de un filme y a la vez un aspecto indisociable de la representación del tiempo y de su confluencia con el movimiento. Jacques Aumont

\footnotetext{
Su aparición ocurre en paralelo con una maquinaria efectivamente diseñada para acelerar el traslado en el espacio: el avión. Edgar Morin hace referencia explícita a este hecho en el primer capítulo de su libro El_cine o el hombre imaginario, homologando el surgimiento de estas dos máquinas que "franquean un 'muro del sonido"». Así también en La imagen-movimiento Gilles Deleuze inserta el aparato cinematográfico en los cambios producidos en el campo de los medios de transporte tras la revolución científica moderna: «El cine parece sin duda el hijo último de este linaje sacado a luz por Bergson. Se podría concebir una serie de medios de traslación (tren, automóvil, avión...) y paralelamente una serie de medios de expresión (gráfica, fotografía, cine): la cámara se aparecería entonces como un intercambiador, o más bien como un equivalente generalizado de los movimientos de traslación» (18).
} 
lo resume en una pregunta: «¿Qué es el movimiento sino el punto de conjunción entre tiempo y espacio?» (77).

Recordemos que la obra de dos volúmenes de Deleuze, nombrada genéricamente Estudios sobre cine, comprende la revisión de dos etapas o dos modos de entender el cine, individualizados como imagen-movimiento e imagen-tiempo ${ }^{3}$. Deleuze se propone una «taxonomía, un ensayo de clasificación de las imágenes y de los signos» (La imagen-movimiento 11), basándose en el ensayo de Bergson Materia y memoria y sus hallazgos acerca del comportamiento de las imágenes en cuanto realidad psíquica:

El descubrimiento bergsoniano de una imagen-movimiento, y más profundamente de una imagen-tiempo, conserva todavía hoy una enorme riqueza, y cabe sospechar que aún quedan por despejar muchas de sus consecuencias. A pesar de la muy sumaria crítica que Bergson hará del cine poco después, nada puede impedir la conjunción de la imagen-movimiento, según él la considera, con la imagen cinematográfica (11).

Tras revisar y comentar cada una de las aproximaciones bergsonianas al análisis de la imagen desde la perspectiva del movimiento, Deleuze traza una línea divisoria entre el cine clásico y el cine moderno, inscritos cada uno en los regímenes planteados, por él, a partir de la lectura de Bergson. El cine moderno rompería, según su postura, con las lógicas de acción-reacción, con el «esquema sensorio-motor» que constituye el pilar estructural del cine clásico. Por su parte, Jacques Rancière -y es esta la perspectiva que me interesa trabajar principalmente- cuestiona la división que Deleuze desarrolla entre cine clásico y cine moderno (como vimos con el primero inscrito en el régimen de la imagen-movimiento y el segundo como una ruptura que oblitera el esquema anterior, a partir de su inscripción en el régimen de la imagen-tiempo). Para Rancière, dicha ruptura no existe como parcelación de dos tipos diferentes de cine, o dos tipos diferentes de imagen, sino que convoca dos perspectivas disímiles acerca de un mismo lenguaje: "Fácilmente concluiremos que la imagen-movimiento y la imagen-tiempo no son en modo alguno dos tipos de imágenes opuestas, correspondientes a dos edades del cine: son dos puntos de vista sobre la imagen» (La fábula 136).

Uno de los puntos que Ranciére revisa y cuestiona de la propuesta de Deleuze es aquel que plantea la idea de parálisis como marca de la ruptura entre el cine clásico

Fundada como una teoría que se desmarca de las principales corrientes de la época, a saber, las aproximaciones realistas fenomenológicas y las semióticas, Deleuze propone una especificidad de la percepción cinematográfica, que articula en función de estas dos nociones principales: imagen-movimiento e imagen-tiempo. «La elaboración de los conceptos de imagen-movimiento y de imagen-tiempo [...] ofrece a Deleuze los medios para producir una semiología propiamente cinematográfica de gran riqueza, y para reorganizar [...] los debates mayores que han atravesado la historia del cine. El concepto de imagen-movimiento permite situar en una nueva perspectiva los debates que conciernen a la relación del montaje con el plano, así como la cuestión de la relación entre cine y narración. El concepto de imagen-tiempo permite, en cambio, dar cuenta de la mutación acaecida en el cine de posguerra, de la fractura entre el 'cine clásico' y el 'cine moderno'. La articulación entre la imagen-movimiento y la imagen-tiempo traza no solo una articulación interna a la historia del cine, sino también una articulación entre el cine, las otras artes y un cierto estado del mundo» (Marrati 8). 
y el moderno. Con algunos ejemplos de la cinematografía de Alfred Hitchcock ( $L a$ ventana indiscreta, Vértigo, Falso culpable), Deleuze grafica de qué manera «la culminación de la imagen-movimiento es también el instante en que esta entra en crisis, en que se rompe el esquema que provocaba situación y reacción, sumiéndonos en un mundo de sensaciones ópticas y sonoras puras» (La fábula 138). Sin embargo, nos dice Rancière, los objetos estudiados provienen de hechos y situaciones encarnados en la ficción narrativa de estas películas, no de las cualidades de la imagen propiamente tal. Desde este punto de vista, la supuesta «crisis» de la imagen-movimiento es provocada por el autor en pos de una necesidad teórica. Pero esto no significa que Deleuze nos engañe, sino que se apoya de los elementos ficcionales para provocar una perspectiva de análisis. Me interesa el asunto de la "parálisis» como estado de transformación de la imagen-movimiento, en cuanto a la conceptualización de la infancia que pretendo analizar en este capítulo, esto es, aquella que refiere a un tipo específico de niño ubicado en las capas bajas de la sociedad, cuya identidad se forjaría en virtud de su movilidad. Adhiriéndome al «método» utilizado por Deleuze y explicitado por Rancière, considero pertinente analizar estos filmes desde el prisma de la imagen-movimiento, en cuanto su narrativa se configura en base a las traslaciones espaciales de sus protagonistas, y teniendo siempre en cuenta que dicha movilidad obedece a un contexto sociopolítico que los fuerza al desplazamiento como estrategia de sobrevivencia.

Uno de los asuntos que Deleuze examina en La imagen-tiempo es precisamente aquel que refiere al «paseo, el vagabundeo (balade), el ir y venir continuo» (289) que el autor confina a los territorios del cine moderno, el de la imagen-tiempo ${ }^{4}$. Este tránsito, nos dice Deleuze, «ha pasado a ser un deambular urbano, y se ha desprendido de la estructura activa y afectiva que lo sostenía, que lo dirigía». En mi lectura de estos filmes, todos ellos anclados en la narrativa del sujeto vagabundo, sigo la propuesta de Rancière, postulando que ellos, a pesar de integrar este paseo urbano, aparentemente liberados de una continuidad direccional del movimiento, pueden ser estudiados desde la perspectiva de la imagen-movimiento -ya veremos de qué manera- cuya estructura de activación está dada por las opciones de traducción de ese movimiento que apelan a un sujeto espectador potencial.

En estas películas, filmadas en la década del sesenta, me propongo explorar el uso del lenguaje cinematográfico con que cada una aborda el deambular de los niños protagonistas. Es también relevante, en este caso, que las corrientes cinematográficas que influyeron en el cine latinoamericano del período, interesadas a su vez en el cine de tipo social -cinema verité, neorrealismo- promovieran la filmación en locaciones reales por sobre la filmación de estudio, decididos a «tomarse las calles», remarcando así también el acto móvil de la cámara que recorre y deambula por la ciudad, considerando que las detenciones son parte del movimiento, como lo son

\footnotetext{
Su énfasis en la noción de vagabundeo puede muy bien vincularse a la perspectiva situacionista de «la deriva como forma de reapropiación desalienada de la ciudad» (Catz 1).
} 
los silencios de la música, o cómo la misma propiedad de la visión humana que «congela» las imágenes permite que veamos el prodigio del movimiento generado por el filme. Así, estas corrientes estéticas consideradas parte del cine moderno de la imagen-tiempo -si seguimos rigurosamente las categorías deleuzianas- pueden a su vez, ahora siguiendo la lectura de Rancière, ser estudiadas inscritas en la perspectiva de la imagen-movimiento, y por ende analizadas también en cuanto «imagen como materia» (136). Como adelanté, mi punto de partida está también anclado en la narración (como los casos de "parálisis» analizados por Deleuze), ya que se trata de historias que retratan efectivamente los tránsitos espaciales de estos niños. Desde allí pretendo desarrollar una lectura que privilegie sobre todo el tratamiento fílmico utilizado en tales recorridos narrativos.

La principal correspondencia que quiero establecer es, por consiguiente, la que relaciona la categoría menor -creada para nombrar a un tipo de infante que por oposición al niño-alumno estático y fijado a su pupitre, se moviliza en el territorio caótico de la calle- con el cine entendido como artefacto que reproduce o interpreta el movimiento, noción que confronta la lectura temporal de la cámara como máquina de pasividad. Esta analogía, que vincula una dimensión sociocultural (la de la infancia marginal catalogada en términos de movilidad espacial) con una perspectiva estética (la imagen-movimiento), comporta en sí un par de problemáticas que es necesario explicitar.

\section{UN ENCUADRE QUE SE ABRE}

Volviendo a Rancière, una de las características del arte moderno sería la importancia del autor como constructor de un lenguaje autorreferente y estático que ya no necesita contar historias o remedar la realidad para producir su arte. Muchos vieron en el cine el arte moderno por excelencia, en la medida que su misma operatividad implicaba una superación del trabajo representacional. Sin embargo, y así lo explica Rancière, «no se dieron cuenta de que la automaticidad misma de la pasividad cinematográfica perturbaba la ecuación estética. A diferencia del novelista o del pintor, ellos mismos agentes de su devenir-pasivo, la cámara no puede no ser pasiva» (El espectador 141). En la temática que trabajo, enfocada en la «movilidad» como energía identitaria, la pasividad de la cámara contrasta con la necesidad de presentar el movimiento, o al menos con la presencia de un autor o de una mirada propia del filme que «produzca» este movimiento. En este sentido, la cámara siempre estática deviene en móvil a partir del juego combinatorio de las imágenes seleccionadas. De allí que las opciones de sintaxis del lenguaje cinematográfico cobren especial importancia en cuanto traducciones del movimiento.

En su breve ensayo «El cine como falso movimiento», Alan Badiou se refiere a este punto para cuestionar la aproximación deleuziana que basa la concepción del cine como imagen-movimiento: 
Un filme opera por lo que retira. En él, la imagen, en primer lugar, está cortada, y el movimiento está trabado suspendido, retornado, detenido. Más esencial que la presencia es el corte, no solo por el efecto del montaje, sino ya, de entrada, por el corte del encuadre y de la depuración dominada de lo visible (20).

En esta investigación, no considero al encuadre como antagónico a la imagenmovimiento, sino en cuanto tensiona esta capacidad para provocar las opciones narrativas y sintácticas que describan el movimiento. El «movimiento falso» es, desde mi punto de vista, una estética del movimiento. El mismo Deleuze estaba prevenido de este problema: «el plano es la imagen-movimiento. En cuanto relaciona el movimiento con un todo que cambia, es el corte móvil de una duración» (La imagen-movimiento 26).

Las tres películas que voy a trabajar utilizan estilos muy diferentes a la hora de presentar el tránsito de sus protagonistas y sus choques con la gramática espacial de la urbe y las normas de las instituciones que los vigilan y controlan. En un periodo en el que los organismos de beneficencia comenzaban a ser cuestionados y mirados con cierta sospecha, la cámara comprometida aboga por la denuncia de las situaciones de injusticia que viven estos niños. Sin embargo, el aparato cinematográfico -como la fotografía, diría Susan Sontag- funciona a partir de un dispositivo que enmarca, o circunscribe una realidad. Sontag, como Badiou, enfatiza la capacidad que el encuadre tiene de segregar, excluir aquello que queda fuera. Me gustaría poner atención aquí, en la perspectiva inversa, de este gesto de fronteras: el de constreñir o limitar también aquello que permanece adentro, evitando así su diálogo con lo que queda fuera, encerrándolo en el encuadre. En este sentido, el impulso de movimiento que describí anteriormente como marca de identidad de los niños de la calle, debe ser contenido y definido por un encuadre que va, en su relación con los otros planos, estableciendo una interpretación de esa fuerza en desplazamiento. Por eso, me interesa prestar atención a la importancia de las decisiones cinematográficas que estos directores asumieron al poner en escena la travesía de los niños callejeros, y así subsanar la tensión entre una cámara que constriñe y una imagen que intenta salir de ese marco, entre la pasividad del ojo mecánico y las opciones dramáticas o estéticas de quien la maneja.

De este enunciado surge a su vez una segunda problemática que enriquece la analogía menor / imagen-movimiento. Las opciones sintácticas y narrativas que intentan romper con la estaticidad del artefacto cinematográfico a fin de representar el desplazamiento de los menores en movimiento, implican a su vez una suerte de tutelaje en mayor o menor grado sobre quien observa. En este cuadro analítico, la dupla se vuelve tríada al incluir una nueva variable: el espectador, cuya construcción está delimitada por la estructura sintáctica del filme. Es posible, entonces, hacer un paralelo entre la noción de espectador emancipado del mismo Rancière y su definición de maestro ignorante, donde el alumno aparece como figura activa de conocimiento. En esta investigación, el niño-menor, al ser reproducido por el 
aparato cinematográfico en su traslación por el espacio, origina un sujeto especular situado al otro lado de la pantalla, al que se le asignan también ciertas estructuras de control a la vez que herramientas de emancipación. Es el mismo Rancière quien establece en El espectador emancipado un vínculo entre esta noción y su desarrollo del alumno emancipado, donde la idea de emancipación nada tiene que ver con lo que comúnmente se relaciona con una reapropiación de la identidad perdida (15), sino que alude a la toma de posición en un lugar igualitario: «que todo hombre del pueblo pueda concebir su dignidad de hombre, tomar conciencia de su capacidad intelectual y decidir su uso» (21). En la lógica que Rancière cuestiona, dicha identidad, asignada por un sujeto en posición jerárquica, puede ser nuevamente recuperada solo gracias a la mediación de ese otro. Si lo analizamos en relación a la figura del espectador, la propuesta es la de rechazar un sistema que circunscribe a quien observa en un lugar de aparente pasividad, para luego ofrecerle abandonar ese espacio y «liberarse» de este mandato estático, dejar de ser espectador. Lo que el autor propone es la reivindicación de ese espacio de la mirada. La propia designación del lugar pasivo del espectador es antiemancipatoria: "¿Por qué identificar mirada y pasividad [...]?» (19). Así, también el menor (por no-alumno) representado en el filme, encuentra en la sala de cine a un potencial alumno (el espectador), dispuesto o no a acatar las normas que la misma cinta impone como reglas de aprendizaje.

Rancière describe un círculo, estructura de represión o de liberación, que el maestro emancipador crea para propiciar que el alumno-espectador salga de él: "Maestro es el que encierra a una inteligencia en el círculo arbitrario de donde solo saldrá cuando se haga necesario para ella misma» (El maestro 18). Siguiendo, entonces, la analogía, el círculo que cada película crea es su propia sintaxis y puede identificarse materialmente con el encuadre cerrado del plano, es un acto de traducción de una serie de sucesos (que en este caso privilegian la lectura del movimiento), y es el espectador el invitado a volverse activo en su trabajo por escapar del cerco y hallar lo que incluso el filme mismo no sabía.

La propuesta de análisis recién descrita cobra mayor relevancia en la medida que se trata de filmes inscritos dentro del período del Nuevo Cine Latinoamericano, cuyo compromiso con el cambio social incluyó una férrea vocación pedagógica que permeó los territorios del campo cultural. El lugar del espectador como potencial alumno, cuyo aprendizaje determinaría su futura independencia, se enmarca dentro de la noción de emancipación opuesta a la descrita por Rancière, la del «embrutecimiento", aquella que subraya la distancia entre el saber de quien enseña y la ignorancia de quien aprende.

El encuadre en el plano, aunque no circular (por aludir a la metáfora utilizada por Rancière), funciona también como límite simbólico a la liberación de quien observa. Tal como el círculo del maestro, las normas del encuadre y sus relaciones con otros planos, y con aquello que queda fuera de su alcance, crean una distancia 
entre el espectador y el saber (o quien lo detenta), pero también pueden entregar las herramientas para salir de él y hallar un conocimiento que se escapa de sus fronteras.

En resumen, poniendo en conjunción lo postulado por Rancière sobre Deleuze, las consideraciones del mismo Deleuze sobre la imagen-movimiento y la perspectiva que explicito respecto del encuadre, surge un punto de partida teórico que podría distinguir como una lucha constante y compleja entre la cámara como máquina de pasividad y los esfuerzos de la película por nombrar activamente aquello que la cámara ya ha dicho, y que al mismo tiempo también es la oposición entre la cámara como máquina de confinamiento (el encuadre) y la decisión cinematográfica de liberar aquello que se captura. La tensión derivada de tales contrastes se vuelve más evidente en el corpus expuesto, ya que se trata de filmes en los que la traducción del movimiento es un asunto fundamental, y a la vez invoca una propuesta de espectador implícito -activo o pasivo- que también dialoga con las posibilidades del infante como fuerza en movimiento.

\section{LARGO VIAJE: EL SUPRAVIGILANTE}

Se suele situar Largo viaje en un espacio de transición entre el cine convencional o «viejo» y el «nuevo cine», cuyos desafíos temáticos y de lenguaje dieron vida al movimiento que llevó el mismo nombre en gran parte de Latinoamérica. Tanto Jacqueline Mouesca en Cine chileno-20 años, como Alicia Vega en Re-visión del cine chileno, se refieren a esta posición transicional de la película principalmente en relación al tratamiento de la escena del «velorio del angelito", cuyos ribetes cuasi documentales visibilizan una tradición popular abordada lejos del costumbrismo. No es mi intención autorizar sin cuestionamientos la existencia y heterogeneidad de este movimiento cinematográfico, pero sí me interesa señalarlo como marca sociocultural de una cierta pertenencia que se desarrolló durante las décadas del sesenta y el setenta en el continente ${ }^{5}$. En ese sentido, Largo viaje queda medio afuera y medio adentro de un manifiesto cinematográfico que, en ese momento, dictó las pautas de aquello que debía ser considerado como discurso legítimamente latinoamericano y antihegemónico. Aldo Francia, director del filme Valparaíso mi amor, en su libro Nuevo cine chileno en Viña del Mar sitúa la cinta de Kaulen dentro del Nuevo Cine Chileno, pero insertándolo en un período previo como antecedente principalmente temático, a la vez que le critica una «factura simbólica falsa y demasiado obvia» (47).

En general, no fueron pocos los reparos que se dejaron oír contra un filme que se consideraba de alguna manera autoritario con su objeto. En una entrevista realizada especialmente para esta investigación, José Román, guionista de Valparaíso mi

\footnotetext{
El llamado Nuevo Cine Latinoamericano convocó estéticas y éticas disímiles que intentaron ser catalogadas bajo una misma etiqueta. Estudios posteriores han venido a cuestionar la legitimidad del discurso unitario, no solo rastreando aquello disonante dentro de una propuesta unívoca o al menos coincidente en ciertas aproximaciones al quehacer artístico, sino también rescatando obras y realizadores que por haber, en ese entonces, sido consideradas externas al compromiso del grupo, carecieron de la debida notoriedad.
} 
amor, crítico de cine y activo miembro del circuito cinematográfico en el período que me ocupa, describió, respecto a la cinta acá analizada, la percepción de los jóvenes cineastas de la época como «el padre que había que matar», reconociendo así una cierta dependencia de estilo que a la vez implicaba una ruptura radical. Zuzana M. Pick, autora de un reconocido estudio sobre el Nuevo Cine Latinoamericano, calificó a la obra de Patricio Kaulen como "paternalista», apelativo que el mismo Francia utilizó agregándole un calificativo al catalogarlo de "paternalismo oficialista», haciendo referencia a las vinculaciones de Kaulen con el gobierno de turno. La alusión al paternalismo se refiere específicamente al tratamiento que se da al personaje del niño y su entorno marginal, sin embargo, es posible explorar en qué medida el filme lo es también respecto de su relación con el espectador implícito que él mismo construye. Me interesa detenerme aquí en cuanto estas apreciaciones hacen referencia a una paternidad que indica una afiliación no deseable de la cual es preciso desprenderse. La cinta es el padre autoritario de una generación que quiere rebelarse y es el padre sobreprotector y controlador de una realidad marginal a la que da visibilidad. Como acabo de señalar, en mi análisis puede entenderse también como la figura de autoridad para un espectador al que instruye acerca de las propias reglas con las que debe ser observado.

Luego de recibir cierta indiferencia en el período inmediatamente posterior a aquel en que fue filmada, por contrastar con el compromiso político radical que se esperaba de los cineastas y por identificarse con una factura más bien convencional y perfeccionista, alejada de las expectativas del "cine imperfecto ${ }^{6}$, en la última década fue tomada en consideración (para lo que fue crucial su mención en el libro Explotados y benditos de Ascanio Cavallo) en cuanto a su aporte como pieza relevante para la historia del cine chileno.

Largo viaje retrata el periplo de un niño marginal por las calles de Santiago. El niño tiene familia, una de clase baja a punto de ser desalojada de la casona antigua que comparte con otras familias. El recorrido del que la cámara será testigo es independiente, motivado por la necesidad de devolverle a su hermanito nacido muerto las alas que le permitan llegar al cielo ${ }^{7}$. Muchos son los obstáculos que causan que su trayectoria, de manera breve y directa, sea desplazada en el tiempo e implique una serie de mínimos desvíos en el itinerario, que finalmente son los que lo llevan a alcanzar su meta. La narrativa del filme es una cuya estructura no admite descuidos. La historia está lo suficientemente bien trenzada como para que cada elemento cumpla una función de enlace que organice a los demás. La crítica destacó que el personaje principal no lo sea tanto como sí un objeto, un hilo conductor en función

\footnotetext{
«Por un cine imperfecto», de Julio García Espinosa, es un texto fundamental para el Nuevo Cine Latinoamericano, que además de reivindicar las dificultades en la realización como parte integrante de un lenguaje del cine del tercer mundo, promovía, en el mismo sentido, un cine abierto a la búsqueda y al error.

7 El «velorio del angelito» es una costumbre campesina que consiste en celebrar la muerte de un recién nacido o niño muy pequeño con una fiesta, en presencia del cadáver vestido de blanco y llevando unas alitas de cartón.
} 
de la narración y en desmedro de su propio desarrollo, como señalan, por ejemplo, Alicia Vega en el libro antes citado (134) y Joaquín Olalla en una reseña aparecida en agosto de 1967 en la revista PEC. Abundan los planos generales y los contraplanos que muchas veces agotan la perspectiva, entregándonos una visión previamente digerida del asunto tratado, donde ningún elemento parece estar allí por casualidad, sino bien entretejido con la trama total (tal como los obstáculos en el tránsito del niño no son sino señuelos que lo guiarán hasta el destino deseado: el Cementerio General $)^{8}$. Lo que podría jugar a su favor en cuanto a claridad narrativa, lo pierde en cuanto a posibilidades dramáticas y expresivas, y también a dinamismo, en un filme que parece traer su propia moraleja cosida al vestido.

\section{CÁMARA DE VIGILANCIA (Y LAS POSIBILIDADES DE BURLARLA)}

Ya vimos que uno de los pilares estructurales de Largo viaje es la presencia de elementos que hacen las veces de conectores de las historias y personajes, cuya presencia otorga continuidad a la narración, convocando en un solo universo historias que ocurren paralelamente y que en función de estos conectores se relacionan como parte de un mismo "plan maestro». Quiero destacar especialmente tres y establecer vínculos entre ellos.

La imagen que da inicio al filme es la de una bandada de pájaros que cruza el cielo. Uno de ellos, la paloma que se salva gracias al tiro errado de un tirador en competencia, va a dar al barrio céntrico en que vive la familia del protagonista, quien la descubre y trata de atraparla. Varias serán las escenas en las que, o bien el ave desata los hechos (por tratar de atraparla o salvarla) o actúa como presencia observadora de lo que ocurre (como cuando el estafador se hace pasar por evangélico para conseguir dinero de los fieles o cuando el niño llega por error a una azotea). En un breve episodio, la paloma es reemplazada por un volantín, el segundo elemento que sirve para vincular a un par de niños con el protagonista, quienes por querer reparar su juguete tratan de quitarle las alitas de papel. El tercer elemento son las mismas alas, las que movilizan al niño en su traslado por la ciudad y, en cuanto son interceptadas por otros que quieren también poseerlas, intensifican su energía traslatoria. Estos tres elementos se vinculan a un espacio en particular: el aire. Todas ellas remiten al acto de volar, ya sea por su propia operatividad como la paloma, por la fuerza del viento como el volantín, o por su carga simbólica como las alas de papel. Todos ellos tienen la propiedad imaginaria o material de trasladarse en las alturas. No es un dato menor en un filme que fue catalogado como «un vía crucis a escala minimalista» (Cavallo 114) y "por lejos la película más cristiana en la historia del cine chileno» (Cavallo 113).

El vínculo que quiero hacer notar es el de estas posiciones aéreas y la perspectiva religiosa. En el filme se sugiere una suerte de voluntad divina que desde su

8 Alicia Vega vinculó estos elementos con una trazado construido por el azar, sin embargo, me inclino por apoyar la tesis de Cavallo, que ve en este entramado los tintes de un plan maestro, al que me referiré más adelante. 
localización celeste privilegiada puede organizar los destinos de los personajes y dar continuidad y coherencia al relato. Esa entidad trascendente puede a su vez vincularse con el Padre por excelencia en la cultura judeocristiana, fuerza generadora de todo lo creado y que todo lo conoce, es decir, Dios. Para el análisis que me ocupa es útil integrar esta apreciación a las nociones de emancipación y control contenidas en las conceptualizaciones del maestro ignorante y el espectador emancipado, para, justamente, contravenirlas. La mirada de Dios, que todo lo sabe y que todo lo coordina desde su lugar de dominación, no puede desafiarse. En ese sentido, tanto los personajes como quien observa deben cuidarse bien de atender sus mandamientos, a riesgo de no hacerlo caerán en la oscuridad interpretativa más absoluta de la sala de proyección. Veamos por qué.

En una película que parece comulgar con la idea de destino guiado por una fuerza superior y con un ojo superlativo que es capaz de abarcar, al menos, toda el área urbana del Gran Santiago de fines de los sesenta, creo relevante revisar de qué estrategias cinematográficas se vale para guiar al ojo inquieto de su potencial espectador. Una de las características que llama la atención respecto de sus opciones estilísticas es el uso recurrente del picado, cuando súbitamente se nos presenta la escena desde un punto de vista de altura extrema, una ubicación aérea que circunscribe un plano general al que podemos situar en lo que Deleuze denomina «saturación», donde los datos independientes se multiplican (La imagen-movimiento 27). Esto, en conjunción con un "punto de vista insólito o paradójico» de altura, cuya puesta en escena implica una cierta verosimilitud de dicha perspectiva:

Pero parecen sometidos a una regla pragmática que no vale únicamente para el cine de narración: a menos que se caiga en un esteticismo vacío, tienen que tener una explicación, tienen que parecer normales y regulares, bien sea desde el punto de vista de un conjunto más vasto que comprenda al primero, bien desde el punto de vista de un elemento en un principio inadvertido, no dado, del primer conjunto (La imagenmovimiento 31).

Si bien el uso del picado descrito aquí podría no ser considerado como insólito, sí adquiere esta característica al dialogar con el resto de los planos previos en la secuencia. Su aparición rompe una cierta continuidad y allí radica su excentricidad, y por otro lado se justifica en la apuesta místico-religiosa del filme. Considero que allí descansa su explicación.

El empleo del picado como visión desde la altura se repite en varias escenas de Largo viaje y es también una constante que incorpora a este particular ángulo un traslado de la mirada, ya sea abriendo el campo visual a través del zoom-back, o restringiéndolo y así destacando un elemento por medio del zoom-in. Pretendo examinar una sección narrativa de la película compuesta por una serie de secuencias que utilizan el picado y que presenta la entrada del niño a la ciudad propiamente tal, en busca del «camino al cielo» para devolverle las alas a su hermano muerto. Tras dejar atrás la zona más residencial del barrio, guiado y luego abandonado por 
el falso ciego estafador, el niño enfrenta por primera vez en el filme el caos urbano desprovisto de toda protección. La primera secuencia de la sección analizada, en la que aparece este recurso, es aquella en la que debe escapar de dos niños mayores que quieren usar el papel de las alitas para reparar su volantín. Lo vemos corriendo, ubicada la cámara a la altura de los edificios, en un paneo que lo sigue en su empeño por escapar en medio del tráfico de peatones y automóviles en pleno centro histórico, y que se detiene con la entrada del niño a la iglesia, cuando levemente se desplaza la mirada hacia arriba, indicando explícitamente la localización a la que ha ingresado. Luego logra burlar a los muchachos y esconder las alitas bajo la pila de agua bendita, pero vuelve a extraviarlas y debe moverse tras una mujer a quien pierde de vista sumergido en la multitud de una manifestación política; la perspectiva en picado vuelve a aparecer. Esta vez se trata de su uso más radical dentro del filme, cuando la altura extrema se combine con el zoom-back y la duración del plano supere los 15 segundos. Así también el contraste del tratamiento visual de la secuencia inmediatamente precedente -el niño sumergido y ahogado entre los manifestantes- le otorga un valor expresivo aún mayor. Tras este fragmento de persecución viene otro, en que nuevamente el recurso del picado aparece, ahora brevemente, para enfatizar el abandono y desorientación del protagonista. Es interesante que, cuando perseguido por la policía que cree que es un ladrón, sea una maquinaria de ascensión -un elevador- la que lo rescate, salvándolo de ser detenido, para llevarlo hasta una azotea llena de palomas en un picado mínimo que nos enseña que una vez que todas han volado hay una que se queda (¿la misma que ha aparecido durante toda la película?) como verificando que los hechos transcurren según lo previsto.

La presencia permanente de la paloma, actante de las alturas, relevada a veces por el volantín y las alas de papel, y que provee una suerte de legitimación de los hechos como integrantes de un plan superior al ficharlos bajo su mirada atenta, funciona como embajadora de una presencia celestial de mayor rango, aquella cuya mirada en picado nos recuerda su capacidad de comprender todo el campo visual. A través de los zoom-in y zoom-back, no hace sino potenciar su habilidad de ver aquello que el espectador -simple mortal- no puede conocer a menos que obtenga su permiso: ya sea internándose en el detalle o abriendo el marco de cada plano. Esta conjunción opera en coherencia con un filme que no juega a los dados, sino que teje en nudos bien cerrados la solidez de su trama. La mirada omnisciente y todopoderosa del filme traduce el movimiento del menor en el diálogo entre planos, pero siempre recordándonos un mapa superior más general al que cualquier intención de dinamismo estará supeditado. El niño protagonista es un menor independizado por su decisión de cambio, pero cuya traslación forma parte de una organización causal trascendente de la que nunca podrá desasirse. El espectador verá limitadas sus posibilidades de sublevación en un filme que a cada momento le recuerda los alcances de su poder, a través del cierre y la apertura del encuadre. Lo que está fuera de él continúa dominado por el ojo mecánico y no admite lecturas rebeldes. 
Sabemos que esta mirada sobrenatural no es sino una investidura del aparato fílmico, construida a través de juegos selectivos de lenguaje. Revisemos ahora qué lugar ocupa el espectador respecto de esta construcción. Es posible abordar desde dos perspectivas el lugar donde se ubica el ojo espectador respecto de la mirada creada por el filme. Una de ellas es la que desarrollara muy tempranamente Béla Balázs en su fundamental libro El film: evolución y esencia de un arte nuevo. Según este autor, una de las particularidades esenciales del cine es «La transformación histórica y decisiva, desde el punto de vista de la filosofía del arte», la cual «sustrajo la conciencia del espectador, eliminando la distancia interior que hasta entonces pertenecía a la esencia de la experiencia artística» (39). Balázs se concentra en estudiar las propiedades identificatorias contenidas en el lenguaje del cine, a través del viaje que la cámara propicia, «arrastrando» la mirada de la audiencia hacia el espacio donde los hechos ocurren:

Es como si lo viéramos todo desde el interior, como rodeados por los personajes del filme. No es preciso que estos nos comuniquen lo que sienten, pues vemos como ellos ven. [...] Pues tus ojos están en la cámara y se identifican con los de las personas que actúan. Estas personas ven con tus ojos. A este acto psicológico le llamamos identificación (39-40).

Desde el ángulo opuesto, asociado al discurso científico-filosófico posilustración que, según Irit Rogoff, liga la visión con las facultades de investigación, verificación, vigilancia y conocimiento (31), el «ojo» vicario que la cinta nos otorga en préstamo puede relacionarse más bien con la distancia objetiva que encarna la visión del vigilante. Anne Friedberg, que estudia los recursos del panóptico, el panorama y el diorama, a fin de establecer conexiones con el espectador de cine, señala que tal como el guardia de la torre central panóptica, este es invisible, sin posibilidad de observarse a sí mismo o de ser vigilado. Según Friedberg, la posición del espectador de cine es una de «omnipotencia visual imaginaria» (398).

Ambas ubicaciones, la identificatoria y la distanciada, poseen la facultad de ver sin ser vistos, pero la primera obtiene este privilegio porque se integra a lo representado, formando parte del universo cerrado de la historia, mientras la segunda lo hace al identificarse con la mirada gélida de la máquina, y desde afuera fantasea con la posesión del saber y el control. Ambos lugares no son permanentes sino intercambiables, y el propio discurso fílmico potenciará uno u otro (reforzando aquella dependencia del espectador respecto de la construcción del filme).

Tal vez sea bueno volver a la parte antes mencionada para graficar esto con un ejemplo. En la secuencia que catalogué como más radical en su uso del picado, tenemos un plano anterior en que el niño se ve inmerso en una manifestación política. Está tratando de seguir a la mujer que se ha llevado las alas cuando súbitamente lo vemos en medio de los manifestantes, visiblemente incómodo, sin saber cómo salir o avanzar. Esta escena se presenta también en un ángulo en picado, a la altura de una persona adulta que desde allí mirara al niño. No se trata de una cámara subjetiva, 
pero la cercanía del plano junto al uso de la cámara al hombro que zigzaguea a causa de la multitud -un recurso escasamente utilizado en el filme- potencia cierta identificación que inmediatamente dialoga con un contrapicado, esta vez desde la espalda del niño, justo cuando el pequeño deja de ser arrastrado por el grupo y queda solo en medio de la vereda sin saber todavía qué hacer. La cámara nos ha llevado a compartir una cercanía con el personaje que es inusual en el filme, y, en una historia contada desde las alturas, a convivir con los padecimientos cotidianos del espacio terrenal. Luego de compartir la angustia del niño, su inestabilidad, su confusión y su desconcierto, el ojo mecánico viaja otra vez hacia el reino de los cielos, para mostrarnos que todo se vincula con un proyecto mayor y más elevado, del que tales preocupaciones no ocupan más que un espacio restringido. El zoom-back es violento y vertiginoso. El niño aparece singularizado en su detención frente a los transeúntes, para luego retomar el paso, inseguro, y desaparecer como uno más en la multitud. En este sentido, el movimiento no es solo el del niño a través de las calles, sino también el de la visualidad de un filme que, encarnado en el ojo superior que todo lo vigila, viaja hacia "adentro» y hacia "afuera», entrando en su objeto para escudriñarlo y alejándose de él para mantenerlo bajo control.

En esta planta de movimiento, horizontal (el avance del niño) y también vertical (la cámara y su uso del zoom en el ángulo picado), la cinta dirige la mirada del espectador hacia una trampa de vigilancia. Quien mira se siente como el protagonista, perdido, desorientado. Luego se ubica en la posición del ojo controlador que mantiene cada detalle bajo su arbitrio, dentro y fuera de la ficción del filme: como el Dios que escribe el destino de los seres humanos y como la cámara que designa los medios y recursos con los cuales narrar dicha historia. Entonces el espectador solo tiene dos opciones: la de pactar con la ficción o la de aceptar las normas del entramado cinematográfico siendo consciente de ellas. En Techniques of the Observer: On Vision and Modernity in the Nineteenth Century, Jonathan Crary utiliza, en lugar del término «espectador» (spectator), la palabra «observador» (observer). Ello en cuanto este último refiere en su etimología al acto de seguir o actuar acorde una serie de reglas observadas ${ }^{9}$, aceptadas, internalizadas. Así, el observador es un producto de su decisión de observar, y surge en concordancia con ese juego normativo. Para Crary, el término espectador implica una connotación de pasividad (la misma que critica Rancière), en cambio observador contiene una fuerza de decisión y acatamiento activos (5-6). Podríamos decir que el espectador de Largo viaje deviene en observador de una serie de normas: las de una historia que se pretende carente de ambigüedades, las de una estética cinematográfica bien apegada a los moldes de la causalidad, las del destino trascendente y la de los veinticuatro cuadros por segundo. Tiene que hacerlo si quiere acceder a su propuesta. Sin embargo, una vez allí, una vez declarado observador, contiene en sí mismo la opción de romper aquellas reglas, de

\footnotetext{
Es interesante que la utilización de este verbo se aplique extensamente a la práctica religiosa, en
} cuanto he destacado este aspecto del filme en cuestión. 
emanciparse, no para volverse actor y dejar de ser espectador, sino para no permitir que su lugar como parte de la audiencia quede reducido a una posición fija.

Ahora bien, en este trazado "paternalista» en el que el filme parece haber definido el trabajo del espectador y haberlo resuelto por él, ¿dónde cabe la posibilidad de emancipación? Volvamos a Rancière, cuya aproximación a la conquista de la autonomía por parte del ignorante y de la audiencia no se vincula a las nociones de distanciamiento de Brecht ni a la participación vital de Artaud. Ambas posiciones no hacen sino condenar el lugar del espectador, al asimilar su estatus a la supuesta pasividad de la mirada. Para Rancière la emancipación:

Comienza cuando se comprende que mirar es también una acción que confirma o que transforma esta distribución de las posiciones. El espectador también actúa, como el alumno o como el docto. Observa, selecciona, compara, interpreta. Liga aquello que ve a muchas otras cosas que ha visto en otros escenarios, en otros tipos de lugares... Así, son a la vez espectadores distantes e intérpretes activos del espectáculo que se les propone (El espectador 20).

En este sentido, incluso para una cinta que se propone como padre protector, que resuelve los vacíos y ubica cada elemento en su lugar como piezas de un puzzle, que echa mano de un montaje orgánico que se resguarda en la lógica del causaefecto, puede abrirse a pesar suyo una lectura en la que el espectador encuentra aquello que antes no había. La estrategia que permitiría abrir el cerco está basada en una pregunta. Rancière describe la necesidad de un tercer elemento mediador entre el profesor y su alumno. Un objeto que permita establecer la igualdad de inteligencias y acepte la distancia como «requisito de toda comunicación». En el caso de El maestro ignorante se trató de un libro, Telémaco. Pero podría ser también un filme. Y he aquí la pregunta: ¿es la película el maestro o el tercer elemento mediador? Si contestamos que el maestro, entonces es preciso aceptar que Largo viaje no es un maestro emancipador, ya que a través de sus estrategias de montaje, de sus perfeccionismo narrativo y de su ética moralista condiciona a un espectador al que considera en una posición inferior, a quien es necesario hacer avanzar hasta el lugar donde se encuentra el maestro. Si, por el contrario, pensamos que el filme es el tercer elemento, entonces solo requeriremos de maniobras de lectura emancipatorias, que puedan desasirse de la dependencia respecto de las claves entregadas por el filme. De hecho, una película basada en la autoridad, como lo es Largo viaje, puede incluso volverse más útil a la hora de entrenar las habilidades de emancipación, porque sus normativas son evidentes. Y aquí quiero poner un ejemplo concreto de la película, basado en la mirada superior aérea que tanto se repite, como un señuelo acerca de la propiedad de la visión. En The Production of Space, Henri Lefevre (cit. en Rogoff 32) desarrolla los alcances de la noción de «espacio transparente», aquel que imprime cierta inteligibilidad, capacidad de aprehensión a la visión. La ilusión de transparencia corre mano a mano con la visión del espacio como inocente, como libre de trampas o lugares secretos. Esta transparencia funciona tal como el plano 
en picado que se posiciona sobre el niño en medio de la ciudad, proponiendo un aire diáfano entre el ojo que mira y lo que es mirado, y es en esta ilusión donde pierde su poder de control. En el filme, como antes señalé, se repite el plano en picado en varias ocasiones, el cual vinculé a su operatividad controladora que no solo funciona desde un guion fuertemente engarzado, sino también en la especificidad de la «mirada» que adquiere a través de sus opciones sintácticas. Utilizo la cita de Rogoff respecto de Lefevre para confrontar esta perspectiva aérea, moralista y moralizante, que supone la sumisión de aquello que se constriñe a su espacio óptico. La visión en altura asume la transparencia de ese espacio entre la máquina que mira y lo mirado, como una metáfora de un filme que se niega a dejar entrar otros sucesos, otros personajes y otras éticas más allá de las que ya han sido reclutadas. Ese aire no es tan diáfano y esconde otras versiones de lo visto, tal como el filme no puede pretender comprender su objeto forjado en la rigidez del relato. Es curioso que el mismo director se planteara esta empresa fílmica desde la vereda opuesta:

Kaulen nos confiesa que él 'no se planteó nada'. No fue hacia el filme con una idea $a$ priori. Quería simplemente que este reflejara una forma de ver el mundo que lo rodeaba con tanta objetividad como pudiera. En el espíritu de los neorrealistas italianos, salió a la calle en busca de una verdad (Silva).

Ese espacio aparentemente «vacío» no es inocente, tal como tal «objetividad» es inalcanzable, sino que contiene toda la carga sociopolítica no solo del universo narrativo del filme, sino también, y sobre todo, de la mirada de la propia cinta, como máquina de pasividad que se activa en sus decisiones estéticas, y que deviene en una entidad determinada por sus pretensiones de control.

Comencé este análisis intentando desentrañar de qué manera un filme tildado de paternalista con su objeto podía serlo también con su espectador implícito. En este intento encuentro que aquellas características que según algunos críticos le otorgan el estatus de «cine adulto» (Silva), las que le dan el carácter de obra bien realizada -interesante además el rango de «adulto» en una investigación que rastrea cómo la institución adulta circunscribe y limita al infante- son las que lo rigidizan en su lenguaje, y así comprimen las posibilidades de emancipación del espectador. El mapa que el director sin embargo arguye no haber compuesto previamente, aparece como estructura fundante de la cinta aun en su nivel simbólico. En este territorio, solo la aceptación consciente y atenta de dichas normas, así como el espectador erigido como observador activo, permitirá que este largo viaje haga visible aquello que la película supuso invisible.

\section{REFERENCIAS}

Ariés, Philippe. «Capítulo II: El descubrimiento de la infancia. El niño y la vida familiar en el Antiguo Régimen». Scribd. Fecha de ingreso: 9 de abril de 2010. <http:// goo.gl/k0rVB>. Sitio web. 
Aumont, Jacques. Las teorías de los cineastas. Barcelona: Paidós, 2004. Medio impreso.

Badiou, Alan. «El cine como falso movimiento». Imágenes y palabras: escritos sobre cine $y$ teatro. Buenos Aires: Manantial, 2005. 19-25. Medio impreso.

Balázs, Bela. El film: evolución y esencia de un arte nuevo. Barcelona: Gustavo Gili, 1978. Medio impreso.

Cavallo, Ascanio. Explotados y benditos: mito y desmitificación del cine chileno de los 60. Santiago: Uqbar, 2007. Medio impreso.

Crary, Jonathan. Techniques of the Observer: On Vision and Modernity in the 19th Century. Cambridge: MIT Press, 1992. Medio impreso.

Deleuze, Gilles. La imagen-movimiento: Estudios sobre cine 1. Barcelona: Paidós 1994. Medio impreso.

---. La imagen-tiempo: Estudios sobre cine 2. Barcelona: Paidós, 1986. Medio impreso.

Francia, Aldo. Nuevo cine latinoamericano en Viña del Mar. Santiago: CESOC Ediciones Chile América, 1990. Medio impreso.

Largo viaje. Kaulen, Patricio dir. Act. Enrique Kaulen, Eliana Vidal, Fabio Zerpa. NaranjoCampos Menéndez, 1967. Film.

Montecino, Sonia. Madres y huachos: alegorías del mestizaje chileno. Santiago: Catalonia, 2007. Medio impreso.

Mouesca, Jacqueline. Cine chileno-20 años 1970-1990. Santiago: Ministerio de Educación, 1992. Medio impreso.

Pick, Zuzana. The New Latin American: A Continental Project. Austin: University of Texas Press, 1993. Medio impreso.

Platt, Anthony. The Child Savers: The Invention of Delinquency. Chicago: University of Chicago Press, 1969. Medio impreso.

Rancière, Jacques. El espectador emancipado. Buenos Aires: Manantial, 2010. Medio impreso.

---. El maestro ignorante. La boca-Barracas: Editorial tieRra del sUr (sic), 2006. Medio impreso.

---. La fábula cinematográfica. Barcelona: Paidós, 2005. Medio impreso.

Rogoff, Irit. «Studying Visual Culture». The Visual Culture Reader. Ed. Nicholas Mirzoeff. London: Routledge, 2002. 24-36. Medio impreso.

Rojas Flores, Jorge. Historia de la infancia en el Chile republicano. Santiago: JUNJI, 2010. Medio impreso.

---. «Los niños y su historia: un acercamiento conceptual y teórico desde la historiografía». Pensamiento Crítico Revista Electrónica de Historia. Nombre del sitio web. Fecha de ingreso: 30 de junio de 2010. <http://goo.gl/7zR3l>. Sitio web.

Salazar, Gabriel. Ser niño «huacho» en Chile (siglo XIX). Santiago: LOM Ediciones, 2006. Medio impreso.

Silva, Mariano. «La crónica de un 'largo viaje' y crítica de Mariano Silva». CIVECHILE: Enciclopedia del cine chileno. Originalmente en Revista ECRAN (1967). <http:// www.cinechile.cl/archivo41>. Sitio web. 
Vega, Alicia. Re-visión del cine chileno. Santiago: Aconcagua, 1979. Medio impreso.

Zapiola, María Carolina. "Los niños entre la escuela, el taller y la calle. Buenos Aires, 1884-1915». Crimen y Sociedad. Fecha de ingreso: 12 de mayo de 2010. <http:// goo.gl/vuGos>. Sitio web.

Recepción: Agosto 2012

Aceptación: Octubre 2012 